\title{
Does preoperative atrial fibrillation increase the risk for mortality and morbidity after coronary artery bypass grafting?
}

\author{
Niv Ad, MD, ${ }^{\text {a }}$ Scott D. Barnett, PhD, ${ }^{\text {a }}$ Constance K. Haan, MD, MS, ${ }^{\mathrm{b}}$ Sean M. O’Brien, PhD, ${ }^{\mathrm{c}}$ Sarah Milford-Beland, MS, ${ }^{\mathrm{c}}$ and
} Alan M. Speir, MD

Objectives: Preoperative atrial fibrillation has been associated with less favorable outcomes in patients undergoing coronary artery bypass grafting. However, it was never investigated in a large cohort of patients using a national database. This study aims to (1) identify the effect of atrial fibrillation on operative mortality and morbidity in patients undergoing isolated coronary artery bypass grafting and (2) identify the potential effect of atrial fibrillation on patients with decreased left ventricular ejection fraction $(\leq 40 \%)$.

\begin{abstract}
Methods: The Society of Thoracic Surgeons National Adult Cardiac Surgery Database was used for patients with coronary artery disease undergoing isolated coronary artery bypass grafting $(n=281,567)$. The association between atrial fibrillation and outcomes was estimated within 3 categories of low (ejection fraction, $<40 \%$ ), moderate (ejection fraction, 40\%-55\%), or normal (ejection fraction, $>55 \%$ ) systolic function.

Results: Patients with atrial fibrillation were found to be older and have a higher incidence of comorbidities. A higher incidence of all major complications and mortality after surgical intervention was documented. An interaction between atrial fibrillation and an ejection fraction of greater than $40 \%$ for mortality, stroke, prolonged ventilation, and prolonged length of stay was identified.

Conclusions: Our findings suggest that preoperative atrial fibrillation is associated with an increased risk for perioperative mortality and morbidity in patients undergoing coronary artery bypass grafting. The negative effect of atrial fibrillation might be more significant in patients undergoing coronary artery bypass grafting with an ejection fraction of greater than $40 \%$. Both the EuroSCORE and, until recently, the Society of Thoracic Surgeons risk calculator do not include atrial fibrillation as a potential risk modifier; however, based on this study, it should be identified as a variable to be investigated and incorporated into future risk calculators.
\end{abstract}

Atrial fibrillation is a very common arrhythmia affecting several million patients with a median age of 70 years in the United States. ${ }^{1}$ The average age for patients treated surgically for ischemic heart disease is increasing, and as a result, it is not uncommon to have candidates for cardiac surgery presenting with concomitant atrial fibrillation. A few large cohort studies have recently recognized atrial fibrillation as a marker for increased cardiovascular morbidity and mortality. ${ }^{2}$ This, together with the increased prevalence of atrial fibrillation in patients undergoing cardiac surgery, makes it important to assess the potential effect of the arrhythmia on outcome after surgical intervention using a large surgical database. Preoperative atrial fibrillation among patients undergoing coronary artery bypass grafting (CABG) has been shown to be associated with higher mortality and morbidity. ${ }^{3,4}$ Nevertheless, atrial fibrillation was never intro-

\footnotetext{
From Inova Heart and Vascular Institute, ${ }^{a}$ Falls Church, Va; the University of Florida College of Medicine-Jacksonville, ${ }^{\mathrm{b}}$ Jacksonville, Fla; and the Duke Clinical Research Institute, ${ }^{\mathrm{c}}$ Durham, NC.

Received for publication July 25, 2008; revisions received Sept 9, 2008; accepted for publication Sept 23, 2008

Address for reprints: Niv Ad, MD, Director of Cardiac Surgery Research, Inova Heart and Vascular Institute, 3300 Gallows Rd, Falls Church, VA 22042 (E-mail:niv.ad@ inova.org).

J Thorac Cardiovasc Surg 2009;137:901-6

$0022-5223 / \$ 36.00$

Copyright (c) 2009 by The American Association for Thoracic Surgery

doi:10.1016/j.jtcvs.2008.09.050
}

duced as a variable in the most commonly used risk calculators for cardiac surgery, such as the EuroSCORE and the Society of Thoracic Surgeons (STS) risk score (as recently incorporated by STS version 2.61), and subsequently has rarely been considered to be a variable of significance when discussing the risk and benefits of the surgical procedure with the referring physicians, payers, and patients.

Theoretically, preoperative atrial fibrillation might pose a higher clinical relevance in patients who present for surgical intervention with a low ejection fraction (EF) and congestive heart failure. In addition, patients with pre-existing atrial fibrillation are at a higher risk for time-related mortality after $\mathrm{CABG}^{2,4}$ However, one of the challenges is to determine whether atrial fibrillation is a marker or causally related factor in less favorable outcomes, and this might require a prospective clinical trial to compare matched groups of candidates for surgical intervention with and without atrial fibrillation. The current literature dealing with this question is based on retrospective reports, most of them based on a single institution's experience. Therefore by using data from the STS Adult Cardiac Surgery Database, the present study was designed to identify the potential effect of preoperative atrial fibrillation on the operative mortality and morbidity in a large cohort of patients with coronary artery disease undergoing isolated CABG to identify the potential association with reduced left ventricular function. 


\section{Abbreviations and Acronyms \\ $\mathrm{CABG}=$ coronary artery bypass grafting \\ $\mathrm{EF}=$ ejection fraction \\ $\mathrm{OR}=$ odds ratio \\ STS $=$ Society of Thoracic Surgeons}

\section{MATERIALS AND METHODS}

This is a prospective cohort observational study using data from the STS National Adult Cardiac Surgery Database data collection platform for surgical data collected during the years 2002 and 2003. This platform allows prospective data collection from multiple institutions with agreed definitions.

Subjects were patients undergoing isolated CABG. The STS data collection versions used were 2.35 and 2.41 . EF was classified as low $(<40 \%)$, moderate $(40 \%-55 \%)$, or normal $(>55 \%)$. Outcomes of interest were operative mortality, reoperation, permanent stroke, prolonged ventilation $(>24$ hours), renal failure, and prolonged postoperative length of stay ( $>14$ days).

Baseline demographic characteristics, preoperative risk factors, and outcomes of interest were compared between patients with and without preoperative atrial fibrillation. Continuous variables were categorized, and all variables were described as frequencies, with $\chi^{2}$ tests for comparisons between groups. We used regression splines to model the association between $\mathrm{EF}$ and the outcome without assuming strict linearity. We first performed unadjusted comparisons and then adjusted for a broad range of patient preoperative characteristics, which included age, body mass index, EF, glomerular filtration rate/dialysis, male sex, white race, smoking status, family history of coronary artery disease, diabetes, hypercholesterolemia, hypertension, cerebrovascular accident, infectious endocarditis, chronic lung disease, immunosuppressive treatment, peripheral vascular disease/ cerebrovascular disease, any previous cardiovascular interventions, triplevessel disease, congestive heart failure, myocardial infarction/timing of myocardial infarction, angina/angina type, resuscitation, New York Heart Association class IV, left main disease, and status/cardiogenic shock. In the CABG combined with mitral valve surgery group, we also adjusted for whether patients had mitral stenosis, moderate-to-severe mitral insufficiency, or both. All adjusted analyses were performed with generalized estimating equation models to account for correlations among clustered responses (eg, within-hospital correlations). Patients without preoperative atrial fibrillation serve as the reference group for all odds ratio (OR) comparisons.

We further investigated whether significant interactions exist between atrial fibrillation and the following continuous variables: EF, age, and body mass index. On finding evidence of a significant interaction effect between atrial fibrillation and EF with respect to several outcomes in the isolated $\mathrm{CABG}$ group, we estimated unadjusted and adjusted ORs for the effect of atrial fibrillation (vs no atrial fibrillation) on complications and mortality within each EF group to serve as comparisons that demonstrate the change in effect caused by adjustment. A $P$ value of less than .05 was considered statistically significant. All analyses were performed with SAS software (version 8.2; SAS Institute, Inc, Cary, NC).

\section{RESULTS}

The prevalence of preoperative atrial fibrillation in patients undergoing operations for isolated $\mathrm{CABG}$ was found to be between $2.7 \%$ in the younger age group to $22.3 \%$ for the 75 - to 80 -year-old patients (Table 1), with a $5.3 \%$ calculated prevalence for the entire group of patients undergoing isolated $\mathrm{CABG}$ and equal distribution between sexes.
Patients undergoing isolated $\mathrm{CABG}$ with preoperative atrial fibrillation presented as older, with decreased EF, and with increased rates of diabetes mellitus, hypertension, and congestive heart failure compared with patients without atrial fibrillation (Table 1).

Among patients undergoing isolated $\mathrm{CABG}$, the presence of preoperative atrial fibrillation is associated with greater rates of all major complications (any reoperation, stroke, prolonged ventilation time, renal failure, prolonged length of stay, and mortality), as shown in Table 2. Patients with preoperative atrial fibrillation undergoing $\mathrm{CABG}$ had higher percentages of renal failure $(6.0 \%$ vs $2.8 \%)$, prolonged hospital stay (ie, postoperative length of stay $>14$ days; $11.3 \%$ vs $5.1 \%$ ), and mortality (5.2\% vs $2.2 \%$ ) than those with no atrial fibrillation (Table 2). Despite adjusting for preoperative patient characteristics, the odds of serious complications and death were all significantly greater for patients with preoperative atrial fibrillation as opposed to those with no preoperative atrial fibrillation (Table 3). Adjusted odds for prolonged length of stay and mortality for those with preoperative atrial fibrillation versus those with no atrial fibrillation were $1.41(95 \% \mathrm{CI}, 1.33-1.49)$ and $1.30(95 \% \mathrm{CI}$, $1.20-1.41)$, respectively.

The relationship between preoperative atrial fibrillation and EF for postoperative complications and mortality in both the unadjusted and adjusted multivariate models is shown in Table 4. There was a significant interaction between atrial fibrillation and EF for mortality, stroke, prolonged ventilation, and prolonged length of stay $(>14$ days) after adjusting for other preoperative characteristics. The effect of preoperative atrial fibrillation (vs no atrial fibrillation) on outcome is greater among patients with an EF of greater than $40 \%$. The adjusted odds of mortality for patients with atrial fibrillation are only 1.17 when compared with patients without atrial fibrillation among the group with an EF of $40 \%$ or less. However, the odds of death for patients with atrial fibrillation are 1.47 and 1.37 compared with patients without atrial fibrillation among those with EFs of $40 \%$ to $55 \%$ and greater than $55 \%$, respectively.

Similarly, adjusted ORs for postoperative length of stay for those with preoperative atrial fibrillation versus those with no preoperative atrial fibrillation are $1.22(95 \% \mathrm{CI}$, $1.12-1.33$ ) among patients with EFs of $40 \%$ or less, 1.56 (95\% CI, 1.42-1.72) among those with EFs of $40 \%$ to $55 \%$, and $1.60(95 \%$ CI, 1.43-1.79) among those with EFs of greater than $55 \%$. There was no strong evidence of an interaction between atrial fibrillation and age or atrial fibrillation and body mass index.

\section{DISCUSSION}

The prevalence of atrial fibrillation among patients undergoing isolated CABG $(5.3 \%)$ is consistent with the reported literature. Patients admitted for CABG with a history of 
TABLE 1. Preoperative demographic and clinical characteristics, 2002-2003

\begin{tabular}{|c|c|c|c|c|c|c|c|c|}
\hline \multirow[b]{3}{*}{ Parameter } & \multicolumn{8}{|c|}{ Isolated CABG } \\
\hline & & \multicolumn{2}{|c|}{ Total } & \multicolumn{2}{|c|}{ No preoperative $\mathbf{A F}$} & \multicolumn{2}{|c|}{ Preoperative AF } & \multirow[b]{2}{*}{$P$ valu } \\
\hline & & $\mathbf{N}$ & $\%$ & $\mathbf{N}$ & $\%$ & $\mathbf{N}$ & $\%$ & \\
\hline \multirow[t]{8}{*}{ Age } & $<50 \mathrm{y}$ & 28,610 & 10.6 & 28,253 & 10.6 & 357 & 2.7 & .001 \\
\hline & $50-55$ y & 29,613 & 10.5 & 28,998 & 10.9 & 615 & 3.9 & \\
\hline & $55-60 y$ & 38,633 & 13.7 & 37,517 & 14.1 & 1116 & 7.8 & \\
\hline & $60-65 y$ & 41,856 & 14.9 & 40,171 & 15.1 & 1685 & 10.7 & \\
\hline & $65-70 y$ & 44,619 & 15.8 & 42,001 & 15.8 & 2618 & 16.6 & \\
\hline & $70-75$ y & 44,905 & 15.9 & 41,469 & 15.6 & 3436 & 21.8 & \\
\hline & $75-80 y$ & 34,344 & 12.2 & 30,823 & 11.6 & 3521 & 22.3 & \\
\hline & $>80 \mathrm{y}$ & 19,105 & 6.8 & 16,694 & 6.3 & 2411 & 15.3 & \\
\hline \multirow[t]{2}{*}{ Sex } & M & 202,290 & 71.8 & 190,908 & 71.8 & 11,382 & 72.2 & .251 \\
\hline & $\mathrm{F}$ & 79,279 & 28.1 & 74,906 & 28.2 & 4373 & 27.8 & \\
\hline \multirow[t]{4}{*}{ EF } & $>55 \%$ & 99,840 & 35.5 & 95,527 & 35.9 & 4313 & 27.4 & .001 \\
\hline & $40 \%-55 \%$ & 110,050 & 39.1 & 104,349 & 39.2 & 5701 & 36.2 & \\
\hline & $30 \%-40 \%$ & 42,081 & 15.0 & 39,136 & 14.7 & 2945 & 18.7 & \\
\hline & $\leq 30 \%$ & 29,716 & 10.6 & 26,916 & 10.1 & 2800 & 17.8 & \\
\hline DM & & 100,494 & 35.7 & 94,473 & 35.5 & 6021 & 38.2 & .001 \\
\hline HTN & & 214,279 & 76.07 & 201,559 & 75.8 & 12,720 & 80.7 & .001 \\
\hline H-Chol & & 199,580 & 70.85 & 189,353 & 71.2 & 10,227 & 64.9 & .001 \\
\hline F Hx CAD & & 120,821 & 42.89 & 115,063 & 43.3 & 5758 & 36.5 & .001 \\
\hline Smoke & & 173,481 & 61.59 & 164,149 & 61.7 & 9332 & 59.2 & .001 \\
\hline CLD & & 53,929 & 19.2 & 49,963 & 18.8 & 3966 & 25.7 & .001 \\
\hline PVD & & 44,926 & 16.0 & 41,432 & 15.6 & 3494 & 22.7 & .001 \\
\hline CVD & & 38,263 & 13.6 & 34,984 & 13.2 & 3279 & 20.8 & .001 \\
\hline CVA & & 20,421 & 7.5 & 18,525 & 7.0 & 1896 & 12.0 & .001 \\
\hline Prv CAB & & 15,098 & 5.4 & 14,022 & 5.3 & 1076 & 6.8 & .001 \\
\hline Prv PTCA & & 56,152 & 19.9 & 53,179 & 20.0 & 2973 & 18.9 & .001 \\
\hline Prv valve & & 729 & 0.3 & 596 & 0.2 & 133 & 0.8 & .001 \\
\hline \multirow[t]{4}{*}{ MI } & $\leq 24$ & 10,442 & 3.7 & 9886 & 3.7 & 556 & 3.5 & .001 \\
\hline & $1-7 \mathrm{~d}$ & 54,705 & 19.4 & 51,007 & 19.2 & 3698 & 23.5 & \\
\hline & $8-21 \mathrm{~d}$ & 9922 & 3.5 & 8962 & 3.4 & 960 & 6.1 & \\
\hline & $>21 \mathrm{~d}$ & 51,739 & 18.4 & 48,687 & 18.3 & 3052 & 19.4 & \\
\hline $\mathrm{CHF}$ & & 39,556 & 14.0 & 34,692 & 13.1 & 4864 & 30.9 & .001 \\
\hline \multirow[t]{2}{*}{ NHYA } & III & 106,665 & 37.9 & 100,328 & 37.7 & 6337 & 40.2 & .001 \\
\hline & IV & 58,110 & 20.6 & 54,027 & 20.3 & 4083 & 25.9 & \\
\hline \multirow[t]{3}{*}{ No. diseased vessels } & 1 & 12,183 & 4.3 & 11,668 & 4.4 & 515 & 3.3 & .001 \\
\hline & 2 & 56,103 & 19.9 & 53163 & 20.0 & 2940 & 18.7 & \\
\hline & 3 & 212,321 & 75.4 & 200,065 & 75.2 & 12,256 & 77.8 & \\
\hline $\mathrm{LM}>50 \%$ & & 70,697 & 25.1 & 66,141 & 24.9 & 4556 & 28.9 & .001 \\
\hline \multirow[t]{3}{*}{ Status } & Elective & 143,094 & 50.8 & 135,970 & 51.1 & 7124 & 45.2 & .001 \\
\hline & Urgent & 126,755 & 45.0 & 118,834 & 44.7 & 7921 & 50.3 & \\
\hline & Emergency & 10,946 & 3.9 & 10,283 & 3.9 & 663 & 4.2 & \\
\hline
\end{tabular}

$\overline{C A B G}$, Coronary artery bypass grafting; $A F$, atrial fibrillation; $E F$, ejection fraction; $D M$, diabetes mellitus; $H T N$, hypertension; $H-C h o l$, hypercholesteremia; $F H x C A D$, family history of coronary artery disease; $C L D$, chronic lung disease; $P V D$, peripheral vascular disease; $C V D$, cerebrovascular disease; $C V A$, cerebrovascular accident; $\operatorname{PrV} C A B$, previous CABG; Prv PTCA, previous percutaneous transluminal cardiac arthroplasty; Prv valve, previous valve; $M I$, myocardial infarction; $C H F$, chronic heart failure; NYHA, New York Heart Association class; $L M$, left main descending.

atrial fibrillation represent, in general, a higher-risk group of patients based on their preoperative clinical variables. Patients with atrial fibrillation are older and have more risk factors for morbidity and mortality.

Previous reports, such as the Framingham Study and a study published by the Cleveland Clinic, documented the same trend in patient outcomes. ${ }^{2,4}$ Other studies published in the past have also identified preoperative atrial fibrillation as a risk factor for early and late mortality, as well as an increased risk for stroke and bleeding., ${ }^{3,5-9}$

Although there were statistically significant interactions between atrial fibrillation and $\mathrm{EF}$ with respect to mortality and several complications, it is questionable whether the interaction effects are clinically significant and truly meaningful. From Table 3, of adjusted ORs for atrial fibrillation versus no atrial fibrillation stratified by EF category, it seems 
TABLE 2. Postoperative outcomes, 2002-2003

\begin{tabular}{|c|c|c|c|c|c|c|c|}
\hline \multirow[b]{3}{*}{ Outcome $(\%$ yes $)$} & \multicolumn{7}{|c|}{ Patients undergoing CABG } \\
\hline & \multicolumn{2}{|c|}{ All } & \multicolumn{2}{|c|}{$\begin{array}{l}\text { No atrial } \\
\text { fibrillation }\end{array}$} & \multicolumn{2}{|c|}{$\begin{array}{c}\text { Atrial } \\
\text { fibrillation }\end{array}$} & \multirow[b]{2}{*}{$P$ valu } \\
\hline & $\mathbf{N}$ & $\%$ & $\mathbf{N}$ & $\%$ & $\mathbf{N}$ & $\%$ & \\
\hline Any reoperation & 17,358 & 6.2 & 15,915 & 6.0 & 1443 & 9.2 & $<.001$ \\
\hline Stroke & 4134 & 1.5 & 3729 & 1.4 & 405 & 2.6 & $<.001$ \\
\hline $\begin{array}{l}\text { Prolonged } \\
\text { ventilation time }\end{array}$ & 21,634 & 7.7 & 19,549 & 7.4 & 2085 & 13.2 & $<.001$ \\
\hline Renal failure & 7943 & 3.0 & 7086 & 2.8 & 857 & 6.0 & $<.001$ \\
\hline $\begin{array}{l}\text { Prolonged } \\
\qquad \text { LOS }>14 d\end{array}$ & 15,257 & 5.4 & 13,472 & 5.1 & 1785 & 11.3 & $<.001$ \\
\hline Mortality & 6759 & 2.4 & 5942 & 2.2 & 817 & 5.2 & $<.001$ \\
\hline
\end{tabular}

that the effect of atrial fibrillation (versus no atrial fibrillation) on outcome is greater among patients with higher EFs (ie, EF $>40 \%$ ). Among patients undergoing CABG, the effect of preoperative atrial fibrillation on outcome was found to be significant, despite adjusting for patient risk factors. Atrial fibrillation is a common endpoint in the natural history of patients with significant mitral valve disease and left atrial enlargement. However, among patients with coronary artery disease and no mitral valve pathology, atrial fibrillation might represent a subset of patients with ischemic
TABLE 3. Unadjusted and adjusted odds ratios for complications and mortality by preoperative atrial fibrillation (versus none) adjusted for potential confounders, patients undergoing CABG only

\begin{tabular}{|c|c|c|c|c|c|}
\hline & Total N & $\begin{array}{c}\text { Unadjusted } \\
\text { OR } \\
\end{array}$ & $\begin{array}{c}95 \% \\
\text { CI } \\
\end{array}$ & $\begin{array}{c}\text { Adjusted } \\
\text { OR } \\
\end{array}$ & $\begin{array}{c}95 \% \\
\text { CI } \\
\end{array}$ \\
\hline Any reoperation & 281,567 & 1.58 & $1.49-1.67$ & 1.18 & $1.12-1.26$ \\
\hline Stroke & 281,567 & 1.85 & $1.67-2.05$ & 1.20 & $1.08-1.33$ \\
\hline $\begin{array}{l}\text { Prolonged } \\
\quad \text { ventilation time }\end{array}$ & 281,567 & 1.88 & $1.79-1.98$ & 1.22 & $1.15-1.28$ \\
\hline Renal failure & 281,567 & 2.19 & $2.04-2.36$ & 1.28 & $1.19-1.37$ \\
\hline $\begin{array}{l}\text { Prolonged } \\
\qquad \text { LOS }>14 \mathrm{~d}\end{array}$ & 281,567 & 2.38 & $2.25-2.51$ & 1.41 & $1.33-1.49$ \\
\hline Mortality & 281,567 & 2.36 & $2.19-2.54$ & 1.30 & $1.20-1.41$ \\
\hline
\end{tabular}

heart disease who should be given special consideration during assessment and counseling on risk in addition to evaluation based on left ventricular EF.

It should be clear that the findings of this study do not suggest that the operative results in general were better among patients with low EFs. However, when comparing the effect of atrial fibrillation on mortality and morbidity within the EF subgroups, preoperative atrial fibrillation increases the odds of a negative effect in patients with EFs of greater than $40 \%$. The addition of EF as a potential modifier for

TABLE 4. Unadjusted and adjusted odds ratios for complications and mortality by preoperative atrial fibrillation adjusted for ejection fraction status and potential confounders, patients with CABG only

\begin{tabular}{|c|c|c|c|c|c|c|c|}
\hline & Total N & Unadjusted OR & $95 \% \mathrm{CI}$ & AF, EF interaction* & Adjusted OR & $95 \% \mathrm{CI}$ & AF, EF interaction* \\
\hline \multicolumn{8}{|l|}{ Any reoperation } \\
\hline $\mathrm{EF} \leq 40 \%$ & 71,766 & 1.46 & $1.33-1.60$ & .4562 & 1.18 & $1.07-1.29$ & .5997 \\
\hline EF $40 \%-55 \%$ & 109,999 & 1.49 & $1.35-1.64$ & & 1.15 & $1.04-1.27$ & \\
\hline $\mathrm{EF}>55 \%$ & 99,802 & 1.60 & $1.43-1.78$ & & 1.25 & $1.11-1.40$ & \\
\hline \multicolumn{8}{|l|}{ Stroke } \\
\hline $\mathrm{EF} \leq 40 \%$ & 71,766 & 1.40 & $1.19-1.64$ & .0021 & 1.02 & $0.86-1.20$ & .0335 \\
\hline $\mathrm{EF} 40 \%-55 \%$ & 109,999 & 2.08 & $1.74-2.48$ & & 1.37 & $1.14-1.64$ & \\
\hline $\mathrm{EF}>55 \%$ & 99,802 & 1.99 & $1.61-2.46$ & & 1.33 & $1.07-1.64$ & \\
\hline \multicolumn{8}{|c|}{ Prolonged ventilation time } \\
\hline $\mathrm{EF} \leq 40 \%$ & 71,766 & 1.52 & $1.42-1.63$ & $<.0001$ & 1.13 & $1.05-1.22$ & .0479 \\
\hline $\mathrm{EF} 40 \%-55 \%$ & 109,999 & 1.92 & $1.75-2.10$ & & 1.30 & $1.19-1.43$ & \\
\hline $\mathrm{EF}>55 \%$ & 99,802 & 1.88 & $1.69-2.09$ & & 1.27 & $1.15-1.41$ & \\
\hline \multicolumn{8}{|l|}{ Renal failure } \\
\hline $\mathrm{EF} \leq 40 \%$ & 65,413 & 1.73 & $1.55-1.93$ & .0007 & 1.15 & $1.03-1.29$ & .0528 \\
\hline EF $40 \%-55 \%$ & 104,537 & 2.27 & $2.02-2.55$ & & 1.35 & $1.19-1.52$ & \\
\hline $\mathrm{EF}>55 \%$ & 96,095 & 2.34 & $2.01-2.72$ & & 1.43 & $1.23-1.66$ & \\
\hline \multicolumn{8}{|c|}{ Prolonged LOS $>14 d$} \\
\hline $\mathrm{EF} \leq 40 \%$ & 71,766 & 1.79 & $1.66-1.94$ & $<.0001$ & 1.22 & $1.12-1.33$ & $<.0001$ \\
\hline $\mathrm{EF} 40 \%-55 \%$ & 109,999 & 2.55 & $2.32-2.81$ & & 1.56 & $1.42-1.72$ & \\
\hline $\mathrm{EF}>55 \%$ & 99,802 & 2.59 & $2.32-2.90$ & & 1.60 & $1.43-1.79$ & \\
\hline \multicolumn{8}{|l|}{ Mortality } \\
\hline $\mathrm{EF} \leq 40 \%$ & 71,766 & 1.80 & $1.62-1.99$ & $<.0001$ & 1.17 & $1.04-1.31$ & .0344 \\
\hline EF $40 \%-55 \%$ & 109,999 & 2.56 & $2.24-2.92$ & & 1.47 & $1.28-1.69$ & \\
\hline $\mathrm{EF}>55 \%$ & 99,802 & 2.41 & $2.03-2.86$ & & 1.37 & $1.16-1.63$ & \\
\hline
\end{tabular}

$C A B G$, Coronary artery bypass grafting; $O R$, odds ratio; $C I$, confidence interval; $A F$, atrial fibrillation; $E F$, ejection fraction; $L O S$, length of stay. ${ }^{*} P$ value for test of interaction score between preoperative atrial fibrillation and ejection fraction. 
postoperative complications and mortality might be suggestive of a causal relationship between preoperative atrial fibrillation and subsequent morbidity. Among patients defined by EFs of greater than $55 \%$, atrial fibrillation is significantly associated with morbidity after adjustment for preoperative risk factors compared with the association seen in patients without atrial fibrillation. In patients predisposed to subsequent postoperative morbidity ( $\mathrm{EF}<55 \%$ ), atrial fibrillation continues to have a significant interactive effect with EF, despite adjustments for traditional risk factors for postoperative morbidity.

The importance of this large-scale study was to establish the clinical association between preoperative atrial fibrillation and increased morbidity and mortality after CABG. However, is there any clinical relevance for these findings? Should preoperative atrial fibrillation be identified as a risk factor to be included in risk-prediction models, such as the STS score? Based on this study, no absolute answer can be given, but the results would suggest that special attention should be given to candidates for $\mathrm{CABG}$ when assessing the operative risk and the expected outcome. The results of the present study should encourage developers of preoperative risk algorithms to consider atrial fibrillation as a risk factor in cardiac surgery preoperative risk algorithms, as was done by the STS, which included preoperative arrhythmia in the risk model for STS version 2.61.

Surgical ablation of atrial fibrillation has been advocated as a useful adjunctive procedure in the care of patients undergoing cardiac surgery and having a documented significant history of atrial fibrillation. The results of the combined and isolated procedure have been very good, with relatively low mortality and morbidity, and have resulted in a significant reduction in the risk for long-term thromboembolic events and strokes. ${ }^{10-13}$ Recent developments in ablation technologies enhance the ability of surgeons to create the different lesions in a very precise and efficient way. ${ }^{14-16}$ Nevertheless, surgical ablation of atrial fibrillation is far from being applied in all cases in which there is an indication for the procedure. Theoretically, ablation of atrial fibrillation in patients undergoing $\mathrm{CABG}$ alone should improve the outcome of the patients and reduce the risk for late strokes. Unfortunately, there are no surgical data stratified by risk factors that can support this assumption. In the electrophysiology literature there are scattered studies to support ablation of atrial fibrillation in patients with low EF, such as the study by Chen and colleagues, ${ }^{17}$ which documented significant improvement in left ventricular function and functional class in patients with low EFs after successful percutaneous ablation. The positive effect of surgical ablation on early outcome is questionable. A meta-analysis of the literature for patients with valve disease and atrial fibrillation revealed improvement in the perioperative results for those patients with a concomitant ablation procedure. ${ }^{18} \mathrm{~A}$ recent publication from the Mayo Clinic ${ }^{19}$ suggested that preoperative atrial fibrillation that was not addressed at the time of $\mathrm{CABG}$ is associated with increased risk for late mortality and morbidity and less favorable long-term survival and therefore recommended surgical correction of atrial fibrillation at the time of CABG.

The question of whether preoperative atrial fibrillation is a marker of sicker patients or causally related to less favorable outcomes after $\mathrm{CABG}$ as a standalone procedure or combined with mitral valve surgery is very important. However, such a causal relationship can only be determined through prospective clinical trials. Lastly, the type of atrial fibrillation is not a variable that is currently being collected by the STS, and therefore the variability in the definition of the arrhythmia by the data collectors in the different centers is uncontrolled. Thus the potential effect of the type of atrial fibrillation could not be determined and should be considered a limitation of the study.

In this study we were able to show, in a large cohort of patients, that preoperative atrial fibrillation is associated with an increased risk for perioperative mortality and morbidity in patients undergoing CABG. Given all the familiar limitations associated with retrospective studies, we can carefully claim that in the low-EF group atrial fibrillation might signal a high-risk patient, and attention should be given when approaching such patients before surgical intervention for discussion of the risks of the surgical procedure. As for patients with good left ventricular function presenting for CABG, the presence of preoperative atrial fibrillation alone might be related to increased morbidity and mortality in which ablation of atrial fibrillation might theoretically improve the outcome. However, such a statement can be supported only after a prospective randomized study. Cardiac surgeons should be familiar with the association between atrial fibrillation and patients' outcome after CABG and also be able to apply modern techniques proved to be effective in treating atrial fibrillation. We also encourage ongoing outcomes studies and clinical research to evaluate developing techniques and their applications and indications to help build the necessary evidence to guide surgeons in their clinical decision making.

\section{References}

1. Feinberg WM, Blackshear JL, Laupacis A, Kronmal R, Hart RG. Prevalence, age distribution, and gender of patients with atrial fibrillation. Analysis and implications. Arch Intern Med. 1995;155:469-73.

2. Benjamin EJ, Wolf PA, D’Agostino RB, Silbershatz H, Kannel WB, Levy D. Impact of atrial fibrillation on the risk of death: the Framingham Heart Study. Circulation. 1998;98:946-52.

3. Sergeant P, Blackstone EH, Meyns B. Validation and interdependence with patient-variables of the influence of procedural variables on early and late survival after CABG.K.U Leuven Coronary Surgery program. Eur J Cardiothoracic Surg. 1997;12:1-19.

4. Quader MA, McCarthy PM, Gillinov AM, et al. Does preoperative atrial fibrillation reduce survival after coronary artery bypass grafting? Ann Thorac Surg. 2004; 77:1514-24.

5. Edwards FH, Gover FL, Shroyer AL, Schwartz M, Bero J. The Society of Thoracic Surgeon National Cardiac Surgery Database: current risk assessment. Ann Thorac Surg. 1997;63:903-8.

6. Sergant P, Blackstone EH, Meyns B. Can the outcome of coronary bypass grafting be predicted reliably? Eur J Cardiothorac Surg. 1997;11:2-9.

7. Wolf PA, Abbott RD, Kannel WB. Atrial fibrillation as an independent risk factor for stroke: the Framingham study. Stroke. 1991;22:983-8. 
8. Odell JA, Blackshire JL, Hodge D, Baily KR. Stroke after coronary artery bypass grafting: are we forgetting atrial fibrillation? Ann Thorac Surg. 2001;71:400-2.

9. Levine MN, Raskob G, Landefeld S, Kearon C. Hemorrhagic complications of anticoagulant treatment. Chest. 2001;119(suppl):108S-21S.

10. Damiano RJ Jr, Gaynor SL, Bailey M, et al. The long-term outcome of patients with coronary disease and atrial fibrillation undergoing the Cox maze procedure. J Thorac Cardiovasc Surg. 2003;126:2016-21.

11. Prasad SM, Maniar HS, Camillo CJ, et al. The Cox maze III procedure for atrial fibrillation: long-term efficacy in patients undergoing lone versus concomitant procedures. J Thorac Cardiovasc Surg. 2003;126:1822-8.

12. Bando K, Kobayashi J, Hirata M, et al. Early and late stroke after mitral valve replacement with a mechanical prosthesis: risk factor analysis of a 24 years experience. J Thorac Cardiovasc Surg. 2003;126:358-64.

13. Cox JL, Ad N, Palazzo T. Impact of the maze procedure on the stroke rate in patients with atrial fibrillation. J Thorac Cardiovasc Surg. 1999;118:833-40.
14. Cox JL, Ad N. New surgical and catheter based modifications of the maze procedure. Semin Thorac Cardiovasc Surg. 2000;12:68-73.

15. Gillinov AM, McCarthy PM, Blackstone EH, et al. Surgical ablation of atrial fibrillation with bipolar radiofrequency as the primary modality. J Thorac Cardiovasc Surg. 2005;129:1322-9.

16. Doll N, Kiaii BB, Fabricius AM, et al. Intraoperative left atrial ablation (for atrial fibrillation) using a new argon cryocatheter: early clinical experience. Ann Thorac Surg. 2003;76:1711-5.

17. Chen MS, Marrouche NF, Khaykin Y, et al. Pulmonary vein isolation for the treatment of atrial fibrillation in patients with impaired systolic function. J Am Coll Cardiol. 2004;43:1004-9.

18. Barnett SD, Ad N. Surgical ablation as treatment for the elimination of atrial fibrillation: a meta-analysis. J Thorac Cardiovasc Surg. 2006;131:1029-35.

19. Ngaage DL, Schaff HV, Mullany CJ, et al. Does preoperative atrial fibrillation influence early and late outcome of coronary artery bypass grafting? J Thorac Cardiovasc Surg. 2007;133:182-9. 